\title{
Evaluation of risk factors for surgical site infection following abdominal surgeries
}

\author{
Roat R. ${ }^{1}$, Damor M. ${ }^{2}$ \\ ${ }^{1}$ Dr. Rajesh Roat, Assistant Professor, ${ }^{2}$ Dr. Mahendra Damor, Associate Professor; both authors are affiliated with \\ Department of General Surgery, Government Medical College, Dungarpur, Rajasthan, India.
}

Corresponding Author: Dr. Mahendra Damor, Associate Professor, Department of General Surgery, Government Medical College, Dungarpur, Rajasthan. Postal Address: 1J-22, Brahamsthali Colony, Near Gyan Sarovar Vatika, Dungarpur (Raj.) Email: docscholar.dr@gmail.com

\begin{abstract}
Objective: surgical site infections (SSIs) are substantial cause of morbidity and mortality among the hospitalized patients. The present study was performed to analyze the incidence of SSIs and to evaluate the risk factors for SSI following abdominal surgeries at a tertiary healthcare centre. Material \& Methods: The present study is a prospective study carried out in the Department of general surgery, Dungarpur Medical College \& Hospital, Rajasthan during the period of 1 year from January 2018 to January 2019. A total of 100 elective and emergency cases of abdominal surgeries were included in the study. Results: 76 patients were male and 24 were female. Age of the patients ranges from 15 to 70 years with the mean age of 52.2 years. Out of 100 procedures, 38 were emergencies and 62 were elective procedures. 11 cases of SSIs were encountered during the study period. Exploratory laparotomy was the surgery most commonly associated with SSIs (4 cases), followed by bowel resection (3 cases) and cholecystectomy ( 2 cases). Conclusion: Post operative surgical site infections causes substantial increase in morbidity and mortality associated with the disease and also increase the healthcare cost. Meticulous surgical techniques, minimizing the duration of operation, proper sterilization, hygienic operation theatres and ward environments are few of the habits which can reduce the risk of SSIs.
\end{abstract}

Keywords: Laparotomy, Surgical site infection, Anti-microbial, Sterilization.

\section{Introduction}

Infections occur in the wound created by surgical procedure are generally referred to as surgical site infections (SSIs). These infections typically occur within 30 days of the surgery at the site or part of the body where surgery took place $[1,3]$.

SSIs are associated with considerable morbidity and it has been reported that more than $1 / 3^{\text {rd }}$ of post-operative deaths are related to SSIs. Besides this, SSI doubles the length of stays in the hospital and thus increases the cost of healthcare. In the past few years so many advances have been achieving in the surgical field to reduce the incidence of SSIs. These include more effective sterilization procedure, laminar flow in the operating room, high efficiency particulate absorbing (HEPA) filters, UV radiation, humidity control, differential temperature and air pressure, surface colony count and antibiotic prophylaxis [4-7].

Manuscript Received: $24^{\text {th }}$ April 2019

Reviewed: $4^{\text {th }}$ May 2019

Author Corrected: $9^{\text {th }}$ May 2019

Accepted for Publication: $14^{\text {th }}$ May 2019
Despite these advances, SSIs remain a substantial cause of morbidity and mortality among the hospitalized patients. The various risk factors responsible for SSIs are emergence of antimicrobial resistant pathogens and various patient related risk factors like age, poor nutritional status, diabetes mellitus, smoking, altered immune response and long post-operative stay [8].

The present study was performed to analyze the incidence of SSIs and to evaluate the risk factors for SSI following abdominal surgeries at a tertiary healthcare centre.

\section{Material and Methods}

Setting: The present study is a prospective study carried out in the Department of general surgery, Dungarpur Medical College \& Hospital, Rajasthan during the period of 1 year from January 2018 to January 2019.

Type of study: Longitudinal prospective study 
Surgical procedures: A total of 100 elective and emergency cases of abdominal surgeries were included in the study. The elective procedure included were hernioplasty,cholecystectomy and resection anastomosis of bowel.

The emergency procedures commonly performed were exploratory laparotomy, appendectomy and resection anastomosis of bowel.

\section{Exclusion criteria}

- Age $<15$ years or $>70$ years

- Patients operated in outpatient services or in minor procedure room

- Patients with associated co morbidities like diabetes/ hypertension/ bronchial asthma/ thyroid disorders/ renal disease or any immunosuppressive disorders

Ethical clearance was taken from ethical committee of our institute.

A detailed informed consent was obtained from all the patients and relatives.

\section{Results}

The present study included 100 emergency and elective cases of abdominal surgery in the surgery department of a tertiary healthcare centre.

76 patients were male and 24 were female. Age of the patients ranges from 15 to 70 years with the mean age of 52.2 years. Out of 100 procedures, 38 were emergencies and 62 were elective procedures. Table 1 show various procedures performed and included in the present study.

Most commonly performed surgery during the study period was inguinal hernioplasty (22\% cases) followed by exploratory laparotomy (21\% cases) and cholecystectomy (19\% cases).

Table-1: Emergency and elective procedures performed in the study.

\begin{tabular}{|c|c|c|c|}
\hline S.No. & Surgery & Total Number & SSI \\
\hline 1 & Inguinal Hernioplasty & 22 & 1 \\
\hline 2 & Cholecystectomy & 19 & 2 \\
\hline 3 & Epigastric hernia repair & 08 & 1 \\
\hline 4 & Bowel resection & 23 & 4 \\
\hline 5 & Exploratory laparotomy & 21 & 0 \\
\hline 6 & Appendectomy & 07 & $\mathbf{1 1}$ \\
\hline
\end{tabular}

11 cases of SSIs were encountered during the study period. Exploratory laparotomy was the surgery most commonly associated with SSIs (4 cases), followed by bowel resection (3 cases) and cholecystectomy (2 cases).

Various risk factors which could be related to SSIs were assessed in the study and are listed in the table 2. 
There was no significant difference between the SSI among male and female population of present study. Various age groups were also equally involved, though percentage of SSI among old age patients (age> 60 years) was little more. Risk of SSI in contaminated wound was significantly greater than the clean wound. The use of drain and longer stay in hospital was found to be associated with more chances of developing SSIs. The chance of developing SSIs was found to be more in emergency procedure $(18.42 \%)$ than the elective procedure $(6.45 \%)$. This could be because emergency cases were commonly associated with contaminated wound.

Table-2: Risk factors assessed in the present study.

\begin{tabular}{|c|c|c|c|}
\hline S.No. & Variables & SSI/Total (\%) & Percentage \\
\hline \multirow[t]{3}{*}{1.} & Gender & & \\
\hline & Male & $8 / 76$ & $10.52 \%$ \\
\hline & Female & $3 / 24$ & $12.5 \%$ \\
\hline \multirow[t]{4}{*}{2.} & Age & & \\
\hline & $<30$ years & $1 / 12$ & $8.33 \%$ \\
\hline & 30-60 years & $6 / 60$ & $10 \%$ \\
\hline & $>60$ years & $4 / 28$ & $14.28 \%$ \\
\hline \multirow[t]{3}{*}{3.} & Wound Type & & \\
\hline & Clean & $4 / 70$ & $5.7 \%$ \\
\hline & Contaminated & $7 / 30$ & $22.58 \%$ \\
\hline \multirow[t]{3}{*}{4.} & Drain used & & \\
\hline & Yes & $4 / 22$ & $18.18 \%$ \\
\hline & No & $7 / 78$ & $8.97 \%$ \\
\hline \multirow[t]{3}{*}{5.} & Hospital stay & & \\
\hline & $\leq 7$ days & $8 / 81$ & $9.87 \%$ \\
\hline & $>7$ days & $3 / 19$ & $15.78 \%$ \\
\hline \multirow[t]{3}{*}{6.} & Type of surgery & & \\
\hline & Emergency & $7 / 38$ & $18.42 \%$ \\
\hline & Elective & $4 / 62$ & $6.45 \%$ \\
\hline
\end{tabular}

\section{Discussion}

The present study showed the SSI rate of $11 \%$ for abdominal surgeries at our institute. Exploratory laparotomy was the surgery most commonly associated with SSIs (4 cases), followed by bowel resection (3 cases) and cholecystectomy ( 2 cases).

The rate of SSI in elective surgery of the present study is comparable to other studies done in other developing countries. A similar study was done by Raka L et al in 2007, on surgical site infections in an abdominal surgical ward of Kosova teaching hospital. A total of 253 surgical interventions were evaluated and they found the overall incidence of SSIs in their study was $12 \%[10]$.

There was no significant difference between the occurrence of SSIs in Male and female in our study ( $10.52 \%$ in male and $12.5 \%$ in female). But, the old age ( $>60$ years) was found to be associated with greater risk of developing SSIs. The percentage of SSIs in older population was $14.28 \%$ while it was $10 \%$ in age group of 30-60 years and $8.33 \%$ in the age group of $<30$ years. This was may be due to the fact that older people have decreased physiological defense mechanism and poor immune system. Similar results were obtained by Kumar et al in their study of prevalence of SSIs. They found the incidence of SSIs in age groups of $<30$ years, $30-60$ years and $>60$ years were $10.9 \%, 13.2 \%$ and $16.9 \%$. The results were very much similar to that of present study. [11].

Keping Cheng et al studied on 1138 patients of SSIs and found that incidence of SSI was $3 \%$ in age group $<75$ years and was $5.6 \%$ in age group $>75$ years [12].

The incidence rate of infections according to surgical procedures was highest for exploratory laparotomy (19.04\%) followed by bowel resection (13.04\%) and 


\section{Original Research Article}

cholecystectomy $(10.52 \%)$. These rates are similar to those reported by European studies, and by the U.S. NNIS reports[13-16]. The present study reported a higher rate of SSI in contaminated wound (22.58\%) than clean wound $(5.7 \%)$. The results are similar to other previous studies. Prospero E et al performed a similar study of surveillance for surgical site infection after hospital discharge on 264 patients. They found that $10.7 \%$ cases of SSIs involved clean sites, $78.6 \%$ involved clean-contaminated sites and $10.7 \%$ cases involved contaminated site[14].

In the present study, the placement of drain showed increases chance of SSIs (18.18\%) than non-placement of drain $(8.97 \%)$. External contamination and subsequent retrograde infection through drain surface can increase risk of SSIs. To prevent or decrease the chances of infection due to drain, closed vacuum suction drains should be used instead of open corrugated drains. The rate of developing SSIs in present study was more in emergency cases $(18.42 \%)$ than elective cases $(6.45 \%)$. This is in accordance to previously reported studies wherein emergency surgeries have shown higher rate of SSI [17-21].

This could be because emergency surgeries usually involved contaminated wound, antibiotic prophylaxis was not given and the duration of surgery was longer with longer postoperative hospital stay. The most common pathogens associated with SSI in the present study were beta hemolytic streptococci and staphylococcus aureus. Staphylococcus aureus is commonly found in anterior nares and skin of humans, and might be responsible for causing infection of wound postoperatively.

The present study was carried out to identify some preventable risk factors associated with SSIs after abdominal surgeries. Identification of such risk factors is expected to help surgeons improve patient care and decrease mortality and morbidity as well as the hospitalcare cost of surgical patients.

\section{Conclusion}

Post- operative surgical site infections causes substantial increase in morbidity and mortality associated with the disease. Hospital stay of the patients with SSIs is increased and leads to increase in cost of healthcare. In present study we tried identifying few of preventable risk factors that can lead to SSIs. Older age, contaminated wound, placement of simple drain and longer hospital stay are few of risk factors that are associated with SSIs. Development of SSIs cannot be completely eliminated but the reduction in the rate is desirable. Meticulous surgical techniques, minimizing the duration of operation, proper sterilization, hygienic operation theatres and ward environments are few of the habits which can reduce the risk of SSIs.

This type of study was not done in the past in the tribal area of Rajasthan so the results of the study are expected to help in reducing the preventable risk factors for SSIs in the area.

Limitations: Limitations of the study should be emphasized. First, the number of study group was not very large (100 patients). Operating room discipline, variability of patients group and various observer differences were the points of limitations in present study which likely weakened the result of our study.

Conflict of interests: The author(s) declared no potential conflicts of interest with respect to research, authorship and /or publication of this article.

Funding: The author received no financial support for the research or publication of this article.

Author contribution: Dr. Mahendra Damor conceived and planned the study project. Dr. Rajesh Roat performed the analytic calculations, numerical simulations and wrote the paper. Dr. MahendraDamor further supervised and finalized the study.

Conflict of interest: None declared.

Funding: Nil, Permission from IRB: Yes

\section{References}

1. Horan TC, Gaynes RP, Martone WJ, et al. CDC definitions of nosocomial surgical site infections, 1992: a modification of CDC definitions of surgical wound infections. Infect Control Hosp Epidemiol. 1992 Oct; 13(10):606-8.

2. Barie PS, Wilson SE. Impact of evolving epidemiology on treatments for complicated skin and skin structure infections: the surgical perspective. J Am Coll Surg. 2015 Jan;220(1):105-116.e6. doi: 10.1016/j. jamcollsurg. 2014.02.039. Epub 2014 Nov 21.

3. Horan TC, Andrus M, Dudeck MA. CDC/NHSN surveillance definition of health care-associated infection and criteria for specific types of infections in the acute care setting. Am J Infect Control. 2008 Jun;36 (5): 309-32. doi: 10.1016/j.ajic.2008.03.002. 


\section{Original Research Article}

4. Berard F, Gandon J. Postoperative wound infections: the influence of ultraviolet irradiation of the operating room and of various other factors. Ann Surg. 1964 Aug;160 (Suppl 2):1-192.

5. Kampf G. The six golden rules to improve compliance in hand hygiene. J Hosp Infect. 2004 Apr; 56 Suppl 2:S3-5. DOI:10.1016/j.jhin.2003.12.023

6. Tumia N, Ashcroft GP. Convection warmers--a possible source of contamination in laminar airflow operating theatres?J Hosp Infect. 2002 Nov;52(3):171-4

7. Brandt C, Hott U, Sohr D, et al. Operating room ventilation with laminar airflow shows no protective effect on the surgical site infection rate in orthopedic and abdominal surgery. Ann Surg. 2008 Nov;248(5): 695-700. doi: 10.1097/SLA.0b013e31818b757d.

8. Mangram AJ, Horan TC, Pearson ML, et al. Guideline for Prevention of Surgical Site Infection, 1999. Centers for Disease Control and Prevention (CDC) Hospital Infection Control Practices Advisory Committee. Am J Infect Control. 1999 Apr;27(2):97132; quiz 133-4; discussion 96.

9. Horan TC, Andrus M, Dudeck MA. CDC/NHSN surveillance definition of health care-associated infection and criteria for specific types of infections in the acute care setting. Am J Infect Control. 2008 Jun;36 (5):309-32. doi: 10.1016/j.ajic.2008.03.002.

10. Raka L, Krasniqi A, Hoxha F, et al. Surgical site infections in an abdominal surgical ward at Kosovo Teaching Hospital. J Infect Dev Ctries. 2007 Dec 1;1 (3): 337-41.

11. Anshul kumar, Arpita Rai. Prevalance of surgical site infection in general surgery in a tertiary care centre in India. Int Surg J. 2017 Sept; 4(9): 3101-3106.

12. Keping Cheng, Jiawei Li, Qingfangkong, Changxian Wang, Nanyuan Ye, Guohua Xia. Risk Factors for surgical site infection in a teaching hospital: A prospective study of 1,138 patients. Patient Preference and Adherence 2015 Aug; 9: 1171-1177.doi: 10.2147/ PPA. S86153

\section{How to cite this article?}

Roat R, Damor M. Evaluation of risk factors for surgical site infection following abdominal surgeries. Surgical Update: Int J surg Orthopedics. 2019;5 (2):105-109.doi:10.17511/ijoso.2019.i02.07.
13. Brandt C, Sohr D, Behnke M, et al. Reduction of surgical site infection rates associated with active surveillance. Infect Control Hosp Epidemiol. 2006 Dec; 27 (12):1347-51. Epub 2006 Nov 21. DOI:10.1086/ 509843

14.Prospero E, Cavicchi A, Bacelli S, et al. Surveillance for surgical site infection after hospital discharge: a surgical procedure-specific perspective. Infect Control Hosp Epidemiol. 2006 Dec;27(12):1313-7. Epub 2006 Nov 21.

15. Fiorio M, Marvaso A, Viganò F, et al. Incidence of surgical site infections in general surgery in Italy. Infection. 2006 Dec;34(6):310-4. DOI:10.1007/s15010006-6632-0

16.Semiannual report aggregated data from the National Nosocomial Infections Surveillance (NNIS) System June 2000. Available at [http://www.cdc.gov/ncidod/ dhqp/pdf/nnis/une2000sar.pdf].

17. Tripathy BS, Roy N. Post-operative wound sepsis. Ind J Med.1984;46 (6):285-8.

18. Chapter IV Factors Influencing the Incidence of Wound Infection. Ann Surg. 1964 Aug;160(Suppl 2): 32-81.

19. Cruse PJE. Surgical wound infection. In: Gorbach SL, Bartlett JG, Blacklow NR editors. Infectious diseases. WB Saunders Company, Harcourt Brace Jovanovich, Inc.: Philadephia, London, Toronto, Montreal, Sydney, Tokyo; 1992: Vol. 16; issue 1:73864. http://doi.org/10.1002/hep.1840160142

20. Beck WC, Deshmukh N. Surgical infections. In: Groschel D, editor. Handbook on hospital associated infections in the general hospital population and specific measures of control. Marcel Dekker, Inc: New York, Basel; 1979; Vol. 3 (1): 1-24.

21. Cruse PJ, Foord R. A five-year prospective study of 23,649 surgical wounds. Arch Surg. 1973 Aug;107(2): 206-10. 